elsewhere, perhaps more than once. The bibliographic software developed to assist with formatting citations only encourages the problem, in that individuals and institutions are compelled to spend their limited money on products that require scientists to spend time learning software rather than doing research. And, of course, the software does not encourage progress toward standardization.

A common citation format, familiar to all, would be sensible. It has been achieved for online versions of papers with the Digital Object Identifier system (DOI), so it should be possible for print journals. Coordination could be undertaken by an organization such as the International Council for Science via its committee on dissemination of scientific information, or the Society for Scholarly Publishing. Certainly, the substance of papers in journals is more important than uniquely stylized references. Time is precious to scientific pursuit, and time wasted retards discovery.

David M. Leslie, Jr*, Meredith J. Hamilton $\dagger$ ${ }^{\star}$ US Geological Survey, Oklahoma Cooperative Fish and Wildlife Research Unit, 404 Life Sciences West, Oklahoma State University, Stillwater,

Oklahoma 74078, USA

$\dagger$ Department of Zoology, Oklahoma State

University, Stillwater, Oklahoma 74078, USA

\section{Writing: visuals are another story}

Sir - Your News Feature "Clear as mud"1 highlights an important issue. The course on effective writing that we run for $\mathrm{PhD}$ students here has taught us that instruction on elements of graphic design (one of us, K.M.F., is a medical illustrator) complements very well the linguistic aspects you address.

We see writing a paper as a business of integrating written and visual information. Scientists are prone to create over-elaborate graphs, charts and other illustrations which inadequately highlight key data. This may actually make a good text more difficult to read. Even when a lot of data need to be included, the manageable information content needs to be taken into account by the author.

For instance, a table containing 17 columns and 7 rows provides necessary documentation but has little visual impact (see, for example, Table 2 of ref. 2). Such tables have greater impact when they are large enough to allow balanced inclusion of text and numerical data (as in Table 1 of ref. 3). Also, complex tables can be made clearer to read by descriptions using full words rather than numerous abbreviations. When experimental results are presented, panels showing single comparisons between control and experimental groups (as in Fig. 4 of ref. 4 ) have a visual advantage over graphs that show multiple experiments on the same axis (see Fig. 3 of ref. 5).

Scientific journals often insist on a very traditional, bland presentation of text and graphics. Perhaps a more creative approach to this on the part of editors would benefit writers and readers alike.

To summarize, before an author submits a paper to a journal, he or she should ask what kind of visual impact it has. Attention to this question would not only improve the paper's readability but would also allow referees to concentrate on data without getting frustrated by the lack of clarity. It might even decrease the rejection rate of essentially good papers. Marek H. Dominiczak, Kathy McFall Medical Humanities Unit, Gartnavel General Hospital, 1053 Great Western Road,

Glasgow G12 OYN, UK

1. Knight, J. Nature 423, 376-378 (2003).

2. Harborne, L., Fleming, R., Lyall, H., Norman, J. \& Sattar, N, Lancet 361, 1894-1901 (2003).

3. Advanced Bladder Cancer (ABC) Meta-analysis Collaboration Lancet 361, 1927-1934 (2003).

4. Golder, M. et al. Lancet 361, 1945-1951 (2003).

5. Sobngwi, E. et al. Lancet 361, 1861-1865 (2003).

\section{Writing: LEX and flexibility}

Sir - In your News Feature on unclear writing, "Clear as mud" (Nature 423, $376-378 ; 2003)$, a passage is cited from the abstract of a paper of which I am first author: "A somitic compartment of tendon progenitors" (Cell 113, 235-248; 2003).

The passage reads: "We demonstrate that the tendons associated with the axial skeleton derive from a heretofore unappreciated, fourth compartment of the somites. Scleraxis (Scx), a bHLH transcription factor, marks this somitic tendon progenitor population at its inception, and is continuously expressed through differentiation into the mature tendons." The News Feature points out that my second sentence begins with a "brand new term", Scleraxis, and quotes writing instructor Judith Swan as suggesting the following rewrite: "This somitic tendon progenitor population is marked at its inception by the gene Scleraxis $(S c x) \ldots$-.. - reasoning that by first recapping the content of the previous sentence, the writer forms a "bridge" or transition that will better prepare readers to take in the new information.

I would first point out that while my second sentence indeed begins with a new term, it makes the transition, just five words later, back to the content of the previous sentence. More importantly, however, my decision to place Scleraxis at the start of the second sentence, and to make it the subject of the sentence followed by an active verb, was to emphasize that it is only because of this marker and its continuous expression that identification of a somitic tendon progenitor population has become possible. Placing this information later in the sentence obscures the gene's importance to the research and cheats the reader of the excitement of discovery of Scleraxis as well as the somitic tendon progenitor population it marks. In short, Swan's preferences, and mine, come down to a question of nuance and style.

While I agree that science writers should strive for clarity, they must be given the same latitude as writers in other disciplines to temper traditional rules of usage with individual stylistic choices that enhance what they want to communicate. Judging papers by methods such as LEX scores, which measure the ratio of everyday words to jargon, is, in my opinion, underestimating the capacity of science readers to creatively and flexibly handle the jargon, stylistic variations, and idiosyncrasies of interesting science writers. In fact, a bit of stylistic license and rule-bending, and a few new terms sprinkled here and there, might even keep the reader curious, challenged and awake. Clarity, yes; but clarity should not be synonymous with absence of style.

\section{Ava Brent}

Department of Genetics, Harvard Medical School, Boston, Massachusetts 02115, USA

\section{Writing: the clear choice}

Sir — It would be interesting to know the accessibility score for G. D. Gopen and J. A. Swan's paper “The science of scientific writing” (Am. Sci. 78, 550-558; 1990), cited in your News Feature about clarity (Nature 423, 376-378; 2003). I use this article in a course I teach. Although it makes some useful points, the students and I think it is overlong and full of unnecessarily complicated words and long-winded sentences.

Writing workshops are great but not widely available. As an alternative, I highly recommend the workbook Essentials of Writing Biomedical Research Papers by Mimi Zieger (McGraw-Hill, New York, 2000) — it works!

Sheila McCormick

Plant Gene Expression Center, USDA/ARS-UC-Berkeley, 800 Buchanan Street, Albany, California 94710, USA

\section{correspondence}

Contributions to Correspondence may be submitted to corres@nature.com. They should be no longer than 500 words, and ideally shorter. 